\title{
Effects of drugs on tremor and increase in brain acetylcholine produced by oxotremorine in the rat
}

\author{
B. COX AND D. POTKONJAK*
}

Pharmacology Department, University of Manchester

\section{Summary}

1. In rats the effect of drugs on oxotremorine tremor and oxotremorineinduced increase in brain acetylcholine has been investigated.

2. Reserpine, $( \pm)-\alpha$-methylmetatyrosine and diethyldithio-carbamic acid, drugs which have in common the ability to decrease tissue noradrenaline concentration, inhibited oxotremorine tremor without preventing the oxotremorine-induced increase in brain acetylcholine.

3. ( \pm )-p-chlorophenylalanine, a depletor of tissue 5-hydroxytryptamine, did not inhibit oxotremorine tremor.

4. Phenoxybenzamine and propranolol inhibited oxotremorine tremor, and propranolol was without effect on oxotremorine-induced increase in brain acetylcholine.

5. The toxicity of oxotremorine was increased by reserpine and phenoxybenzamine.

6. The significance of these findings is discussed with regard to the mode of action of oxotremorine.

\section{Introduction}

There have been many reports on the ability of atropine and atropine-like drugs to antagonize tremorine tremor (for references see Friedman \& Everett, 1964). However, reserpine, amphetamine and imipramine also inhibit tremorine tremor (Agarwal \& Bose, 1967 ; Hammer \& Sjoqvist, 1967 ; Morpugo, 1967 ; Patten, Sakamoto, Van Woert, Papavasiliou \& Cotzias, 1964 ; Sjoqvist \& Gillette, 1965). These drugs have in common an interaction with the adrenergic nervous system. The antagonism of oxotremorine tremor has been less well investigated, but imipramine (Spencer, 1966) and dihydroxyphenylalanine in the presence of a monoamine oxidase inhibitor (Everett, 1967) have been shown to be effective antagonists.

It is therefore possible that an adrenergic link is involved in tremorine and oxotremorine tremor. To investigate this hypothesis a number of drugs which interact with adrenergic nerve function have been tested for an effect on oxotremorine tremor. The drugs chosen for the study include $( \pm)$-p-chlorophenylalanine, diethyldithiocarbamic acid, ( \pm )- $\alpha$-methylmetatyrosine, phenoxybenzamine, propranolol and reserpine.

\footnotetext{
* Present address: Sarajevo Institut za Farmakologiju, Medicinski Fakultet, Mose Pijade 6, Yugoslavia.
} 
Cox \& Potkonjak (1969a) have recently shown that oxotremorine tremor was not potentiated by dyflos, an irreversible cholinesterase inhibitor, throwing doubt on the hypothesis that the tremorgenic action of oxotremorine is an indirect effect mediated through acetylcholine release. To investigate this hypothesis further, some of the drugs which antagonize the oxotremorine tremor have also been tested for their effects on the oxotremorine-induced increase in rat brain acetylcholine.

\section{Methods}

Male Wistar rats weighing 190 to $210 \mathrm{~g}$ were used for the tremor recording ; a wider weight range (190 to $250 \mathrm{~g}$ ) was used in the brain acetylcholine experiments.

\section{Brain acetylcholine estimation}

Acetylcholine was extracted from individual rat brains by a method described previously (Cox \& Potkonjak, 1967). The extracts were assayed for acetylcholine on the guinea-pig ileum pretreated with mipafox (N,N'diisopropylphosphorodiamidic fluoride) using a $2 \times 2,4$ point assay with doses given in a 4 block Latin square arrangement. Values for acetylcholine refer to the free base.

\section{Quantitative estimation of tremor}

Tremor was determined by a method described previously (Cox \& Potkonjak, $1969 \mathrm{~b}$ ) in which a rat is placed in a Perspex box attached to a gramophone pick-up head and the output produced by the pick-up in response to movements of the rat is connected to a wide band preamplifier (7P3A) of a Grass Polygraph (Model 7) and to a polygraph integrator (7P10A) to give an integrated value of the tremor recording. Since the oxotremorine tremor in the rat is almost immediate in onset and reaches a maximum in the first 5 min after injection (Cox \& Potkonjak, 1969b) tremor was recorded for a $5 \mathrm{~min}$ period beginning $30 \mathrm{~s}$ after oxotremorine injection. One complete deflection of the integrator pen was given an arbitrary value of 100 tremor units. The pen returned to base-line immediately after reaching full deflection and was also automatically zeroed every $15 \mathrm{~s}$. In all experiments tremor is presented as the mean of twenty $15 \mathrm{~s}$ samples recorded during the standard $5 \mathrm{~min}$. The dose response curves plotted are the corrected curves obtained by subtracting the mean tremor value recorded from rats receiving only the pretreatment drug (the background activity) from the mean tremor recorded from rats receiving both the pretreatment drug and oxotremorine. The times for each drug pretreatment are presented in the text.

\section{Statistical evaluation of results}

Differences between mean brain acetylcholine concentrations were assessed by Student's $t$ test (two-tailed). The Mann-Whitney U test (Siegel, 1956) was used to determine the statistical significance of the differences between the groups of rats in the tremor recording experiments. Unless otherwise stated the criterion of a significant difference between means was $P<0 \cdot 05$.

\section{Drugs}

Acetylcholine chloride and morphine hydrochloride, B.D.H., ( \pm )-p-chlorophenylalanine, Koch-Light, prepared as a suspension with $1 \%$ carboxymethylcellulose and 
injected in a dose volume of $0.5 \mathrm{ml} . / 100 \mathrm{~g}$ rat ; diethyldithiocarbamic acid expressed as the sodium salt, Eastman Chemicals, injection volume $0.2 \mathrm{ml} . / 100 \mathrm{~g}$ rat ; $( \pm)-\alpha-$ methylmetatyrosine, Regis Chemical Company, prepared as a suspension with $1 \%$ carboxymethylcellulose injected in a dose volume of $0.5 \mathrm{ml} . / 100 \mathrm{~g}$ rat ; Mipafox (L. Light) ; oxotremorine as the pure substance ; phenoxybenzamine (Smith, Kline

\& French) solutions for injection were made in polyethylene glycol; propranolol hydrochloride (I.C.I.) ; reserpine (B.D.H.) solutions for injection were made in $2 \%$ ascorbic acid solution. All the drugs were injected intraperitoneally and unless otherwise stated solutions for injection were made up in $0.9 \%$ saline solution and injected in a volume of $0.1 \mathrm{ml} . / 100 \mathrm{~g}$ rat.

Results

\section{Effect of drugs on oxotremorine tremor}

The background activity recorded from saline controls was 42 units. All doses of oxotremorine used gave tremor readings significantly higher. The corrected dose response curve for oxotremorine is shown in Figs. 1,2 and 3. Maximum tremor was recorded with $1 \mathrm{mg} / \mathrm{kg}$; rats injected with $2 \mathrm{mg} / \mathrm{kg}$ suffered convulsions within $2 \mathrm{~min}$, after which time tremor became reduced. None of the rats died after these doses. During the period of tremor signs of parasympathetic stimulation were present, including salivation, lachrymation (chromodacryorrhoea) and diarrhoea.

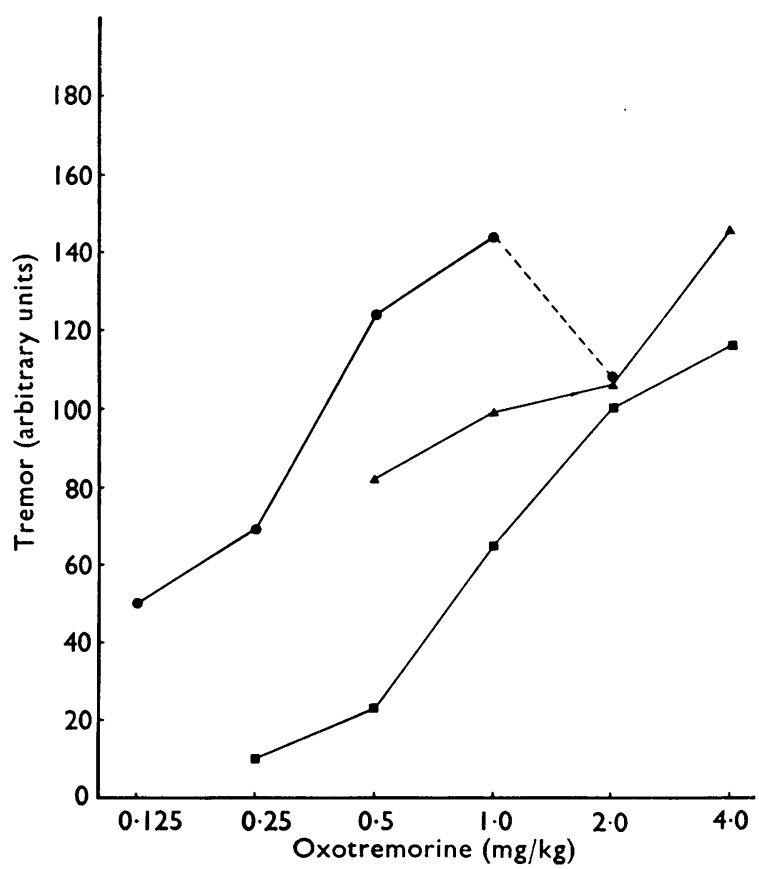

FIG. 1. Effect of reserpine and $( \pm)-\alpha$-methylmetatyrosine on oxotremorine-induced tremor. The corrected mean tremor for oxotremorine plotted against dose of oxotremorine on a log scale. Curves for oxotremorine (O), oxotremorine after reserpine $5 \mathrm{mg} / \mathrm{kg}(\square)$ and oxotremorine after $( \pm)-\alpha$-methylmetatyrosine $400 \mathrm{mg} / \mathrm{kg}(\Delta)$. Each point is the mean of at least five determinations. Mean tremor was corrected by subtraction of the mean tremor value recorded from rats receiving only the pretreatment dose. Interrupted line indicates that mean tremor decreases with increased dose of oxotremorine. 


\section{Reserpine}

Rats were injected with reserpine $5 \mathrm{mg} / \mathrm{kg} 18 \mathrm{hr}$ before an injection of either saline or oxotremorine. This pretreatment with reserpine significantly reduced the background activity in the saline group to 15 units. The dose response curve to oxotremorine showed a significant rightward shift after reserpine (Fig. 1). It remained parallel to the original curve and there was only a slight depression of the maximum tremor recorded. The parasympathetic symptoms were still present. Reserpine also increased the toxicity of oxotremorine; after oxotremorine $1 \mathrm{mg} / \mathrm{kg}$ two rats out of five died within $15 \mathrm{~min}$ of the injection and after $2 \mathrm{mg} / \mathrm{kg}$ four out of five died within $15 \mathrm{~min}$ of the injection.

\section{( \pm )-alpha-methylmetatyrosine}

In rats pretreated with ( \pm )-alpha-methylmetatyrosine $400 \mathrm{mg} / \mathrm{kg} 18 \mathrm{hr}$ before an injection of saline, the recorded background activity was reduced from 42 to 13 units. As with reserpine, the pretreatment with $( \pm)$-alpha-methylmetatyrosine also produced a rightward shift of the oxotremorine dose response curve (Fig. 1). The

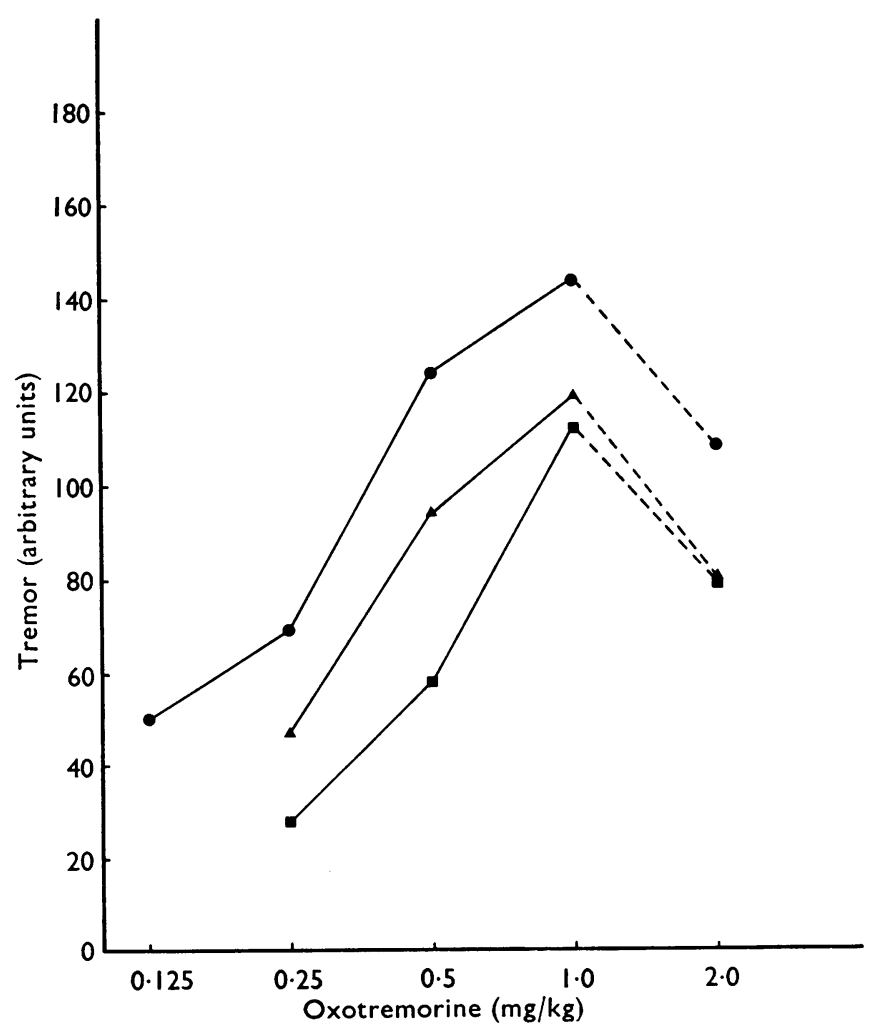

FIG. 2. Effect of diethyldithiocarbamic acid and ( \pm -) $p$-chlorophenylalanine on oxotremorineinduced tremor. The corrected mean tremor for oxotremorine plotted against dose of oxotremorine on a log scale. Curves for oxotremorine ( $)$, oxotremorine after diethyldithiocarbamic acid $500 \mathrm{mg} / \mathrm{kg}$ at 7 and 4 hours before oxotremorine ( $\square$ ), and oxotremorine after $( \pm)$-p-chlorophenylalanine $100 \mathrm{mg} / \mathrm{kg}$ at 24,48 and $72 \mathrm{hr}$ before oxotremorine $(\triangle)$. Each point is the mean of at least five determinations. Mean tremor was corrected by subtraction of the mean tremor value recorded from rats receiving only the pretreatment dose. Interrupted line indicates that mean tremor decreases with increased dose of oxotremorine. 
separation of the curves became more pronounced as the dose of oxotremorine was increased. At $0.5 \mathrm{mg} / \mathrm{kg}$ the difference was not significant $(P=0.075)$, but it became significant $(P=0.004)$ at the $1 \mathrm{mg} / \mathrm{kg}$ dose. There was no evidence of any increased oxotremorine toxicity; the signs of parasympathetic stimulation were present.

\section{Diethyldithiocarbamic acid}

The pretreatment consisted of two injections of $500 \mathrm{mg} / \mathrm{kg}$, one given 7 and the other $4 \mathrm{hr}$ before the oxotremorine. The result is shown in Fig. 2. The rats receiving saline after the diethyldithiocarbamic acid pretreatment had a background activity of 35 units, which was not significantly different from the activity in nonpretreated rats; the rats receiving oxotremorine showed a significant rightward shift of the oxotremorine dose response curve and a depression of the maximum tremor recorded. The maximum occurred at the same dose $(1 \mathrm{mg} / \mathrm{kg})$ as with oxotremorine alone. The pretreatment did not increase the toxicity of oxotremorine and did not abolish its parasympathetic effects.

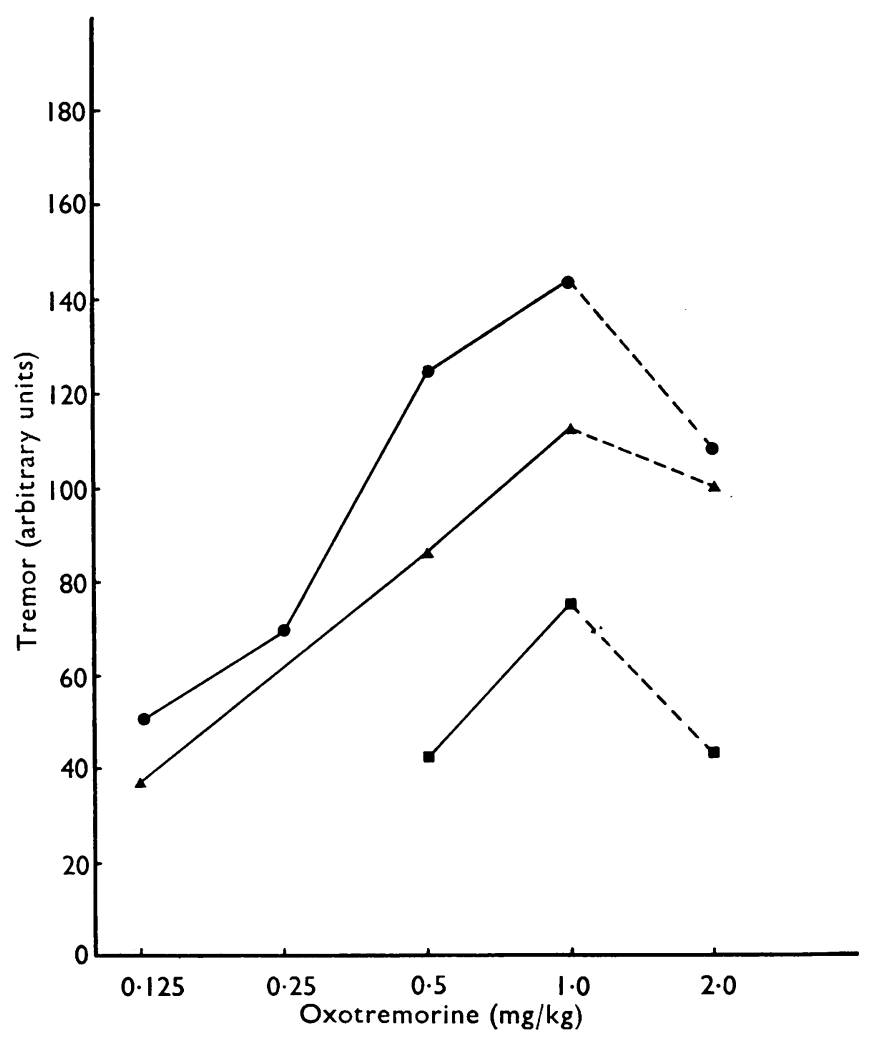

FIG. 3. Effect of propranolol and phenoxybenzamine on oxotremorine-induced tremor. The corrected mean tremor for oxotremorine plotted against dose of oxotremorine on a log scale. Curves for oxotremorine (O), oxotremorine after propranolol $10 \mathrm{mg} / \mathrm{kg}(\Delta)$ and oxotremorine after phenoxybenzamine $20 \mathrm{mg} / \mathrm{kg}$ (D). Each point is the mean of at least five determinations. Mean tremor was corrected by subtraction of the mean tremor value recorded from rats receiving only the pretreatment dose. Interrupted line indicates that mean tremor decreases with increased dose of oxotremorine. 


\section{( \pm )-p-chlorophenylalanine}

The effect of $( \pm)$-p-chlorophenylalanine pretreatment on the oxotremorine tremor is shown in Fig. 2. On 3 consecutive days rats were given injections of $100 \mathrm{mg} / \mathrm{kg}$ and used for tremor recording on the fourth day. The background activity of the pretreated rats injected with saline was 47 units. Up to $1 \mathrm{mg}$ oxotremorine, the dose response curve showed a slight non-significant rightward shift; with $2 \mathrm{mg} / \mathrm{kg}$, tremor was significantly reduced $(P=0 \cdot 048)$. The toxicity to oxotremorine was not increased and the parasympathetic effects were not abolished.

\section{Propranolol}

The effect of pretreatment with propranolol $10 \mathrm{mg} / \mathrm{kg}$, given $60 \mathrm{~min}$ previously, on oxotremorine tremor is shown in Fig. 3. Pretreated rats injected with saline solution had a background activity of 25 units, which was not significantly different from saline control $(P=0.053)$. Tremor recorded in propranolol pretreated rats was not affected after $0.125 \mathrm{mg} / \mathrm{kg}$ oxotremorine, but that recorded after 0.5 and 1 $\mathrm{mg} / \mathrm{kg}$ was significantly reduced. The propranolol did not increase the toxicity to oxotremorine and did not abolish its parasympathetic effects.

\section{Phenoxybenzamine}

The effect of pretreatment with phenoxybenzamine $20 \mathrm{mg} / \mathrm{kg}$ given $18 \mathrm{hr}$ previously on oxotremorine tremor is shown in Fig. 3. Pretreated rats injected with saline solution showed a significant reduction in background activity from 42 to 20 units, and the oxotremorine tremor was greatly reduced. In some rats the toxicity to oxotremorine was increased and its parasympathetic effects did not occur.

\section{Effect of drugs on the oxotremorine-induced increase in brain acetylcholine}

Table 1 summarizes the effects of pre-treatment with reserpine, diethyldithiocarbamic acid or propranolol on the increase in brain acetylcholine produced by

TABLE 1. Effect of drug pretreatment on the increase in rat brain acetylcholine produced by injection of oxotremorine

\begin{tabular}{|c|c|}
\hline $\begin{array}{c}\text { Experiment } \\
\text { No. }\end{array}$ & Drugs \\
\hline 1 & Saline \\
\hline 2 & Oxotremorine \\
\hline 3 & Oxotremorine \\
\hline 4 & Oxotremorine \\
\hline 5 & Reserpine \\
\hline 6 & Reserpine \\
\hline 7 & $\begin{array}{l}\text { Uxotremorine } \\
\text { Reserpine }\end{array}$ \\
\hline & Oxotremorine \\
\hline 8 & $\begin{array}{l}\text { Reserpine } \\
\text { Oxotremorine }\end{array}$ \\
\hline 9 & Diethyldithiocarbamic acid \\
\hline 10 & $\begin{array}{l}\text { Diethyldithiocarbamic acid } \\
\text { Oxotremorine }\end{array}$ \\
\hline 11 & $\begin{array}{l}\text { Diethyldithiocarbamic acid } \\
\text { Oxotremorine }\end{array}$ \\
\hline $\begin{array}{l}12 \\
13\end{array}$ & $\begin{array}{l}\text { Propranolol } \\
\text { Propranolol } \\
\text { Oxotremorine }\end{array}$ \\
\hline 14 & $\begin{array}{l}\text { Propranolol } \\
\text { Oxotremorine }\end{array}$ \\
\hline
\end{tabular}

\begin{tabular}{|c|c|c|c|c|}
\hline $\begin{array}{c}\text { Dose } \\
(\mathrm{mg} / \mathrm{kg})\end{array}$ & $\begin{array}{l}\text { Time after } \\
\text { oxotre- } \\
\text { morine } \\
\text { (min) }\end{array}$ & $\begin{array}{l}\text { Pre- } \\
\text { treatment } \\
\text { time } \\
\text { (hr) }\end{array}$ & $\begin{array}{c}\text { Amount of } \\
\text { brain } \\
\text { acetylcholine } \\
(\mu \mathrm{g}+\mathrm{g} \pm \text { S.E. })\end{array}$ & $\begin{array}{c}\text { Number } \\
\text { of } \\
\text { animals }\end{array}$ \\
\hline - & - & - & $1.49 \pm 0.09$ & 5 \\
\hline 2 & 5 & - & $2.48 \pm 0.45$ & 5 \\
\hline 2 & 15 & - & $2.78 \pm 0.49$ & 7 \\
\hline $\begin{array}{l}2 \\
5\end{array}$ & 30 & 18 & $\begin{array}{l}3.22 \pm 0.51 \\
1.34+0.08\end{array}$ & $\begin{array}{l}5 \\
4\end{array}$ \\
\hline 5 & & 18 & $2 \cdot 17 \pm 0 \cdot 23$ & 5 \\
\hline 5 & 3 & 18 & $2 \cdot 15 \pm 0 \cdot 12$ & 5 \\
\hline $\begin{array}{l}2 \\
5\end{array}$ & 15 & 10 & & 5 \\
\hline $\begin{array}{l}5 \\
2\end{array}$ & 30 & 18 & $1 \cdot 77 \pm 0 \cdot 12$ & 5 \\
\hline $\begin{array}{l}500 \times 2 \\
500 \times 2\end{array}$ & & $\begin{array}{l}7 \text { and } 4 \\
7 \text { and } 4\end{array}$ & $\begin{array}{l}2 \cdot 29 \pm 0.11 \\
2 \cdot 34 \pm 0.20\end{array}$ & $\begin{array}{l}8 \\
5\end{array}$ \\
\hline$\frac{2}{500^{2} \times 2}$ & 15 & 7 and 4 & $3 \cdot 35+0 \cdot 18$ & 4 \\
\hline 2 & 30 & & & \\
\hline 10 & 一 & 1 & $1 \cdot 70 \pm 0 \cdot 11$ & 4 \\
\hline 10 & 5 & 1 & $1.80 \pm 0.09$ & 4 \\
\hline $\begin{array}{r}10 \\
2\end{array}$ & 15 & 1 & $2 \cdot 31 \pm 0.25$ & 5 \\
\hline
\end{tabular}


oxotremorine $2 \mathrm{mg} / \mathrm{kg}$. As seen from the experiments Nos. 1 to 4 of the table, this dose of oxotremorine caused a progressive increase in brain acetylcholine when examined $5(0.1>P>0.05), 15(P>0.05)$ and $30(P>0.001)$ min after the injection.

\section{Reserpine}

Experiment No. 5 of the table shows that a dose of $5 \mathrm{mg} / \mathrm{kg}$ had no significant effect on the acetylcholine content of the brain $18 \mathrm{hr}$ after the injection. When the oxotremorine was injected at this time and the acetylcholine content examined 5 and 15 min later there was, as shown in experiments Nos. 6 and 7, an increase to the same extent as observed in the non-pretreated groups of rats (experiments Nos. 2 and 3 ), but the increase did not progress because $30 \mathrm{~min}$ after the oxotremorine injection the acetylcholine content had again fallen (experiment No. 8) and was in fact not significantly higher than that obtained in the saline control group (experiment No. 1). As reserpine increased the toxicity of oxotremorine, however, some rats in experiment No. 8 died before the end of the scheduled $30 \mathrm{~min}$ period of drug action.

\section{Diethyldithiocarbamic acid}

Experiment No. 9 of the table shows that $500 \mathrm{mg} / \mathrm{kg}$ given twice, once $7 \mathrm{hr}$ and once $4 \mathrm{hr}$ before the rats were killed, had produced a significant increase in the brain acetylcholine. When the oxotremorine was injected $4 \mathrm{hr}$ after the second injection and the acetylcholine content examined 15 and 30 min later, there was a further increase at 30 but not at $15 \mathrm{~min}$ (experiments No. 11 and No. 10). The acetylcholine content in these two conditions was not significantly different from that obtained 15 and 30 min after the oxotremorine injection in the non-pretreated group of rats (experiments No. 3 and No. 4).

\section{Propranolol}

Experiment No. 12 of the table shows that a dose of $10 \mathrm{mg} / \mathrm{kg}$ had no significant effect on the acetylcholine content of the brain, examined $1 \mathrm{hr}$ after the injection. When the oxotremorine was injected at this time and the acetylcholine content examined 5 and 15 min later there was a significant increase only at 15 but not at $5 \mathrm{~min}$, as shown in experiments Nos. 14 and 13, and the increase was not significantly different from that in experiment No. 3 obtained in non-pretreated rats $15 \mathrm{~min}$ after the oxotremorine injection.

\section{Discussion}

The present results show that drugs which cause depletion of tissue noradrenaline inhibited oxotremorine tremor. Thus reserpine, diethyldithiocarbamic acid and $( \pm)$ - $\alpha$-methylmetatyrosine reduced the intensity of the tremor symptoms. Reserpine, which causes depletion not only of noradrenaline but of dopamine, 5-hydroxytryptamine (5-HT), histamine and gamma-aminobutyric acid as well (for comprehensive review see Carlsson, 1956), was the most effective of the three drugs. However, diethyldithiocarbamic acid, which causes depletion of noradrenaline without depletion of either dopamine or 5-HT (Carlsson, Lindqvist, Fuxe \& Hokfelt, 1966), was also an effective antagonist, whereas $( \pm)$ - $\alpha$-methylmetatyrosine, which in the dose used reduced brain noradrenaline to $25 \%$ of its original level (Hess, Connamacher, Ozaki \& Udenfriend, 1961) was the least effective of the three drugs. On the other 
hand, ( \pm )-p-chlorophenylalanine, a specific depletor of tissue 5-HT (Koe \& Weissman, 1966) was without significant effect on tremor produced by oxotremorine $1 \mathrm{mg} / \mathrm{kg}$, the dose found to produce maximal tremor. All these results provide evidence suggesting that depletion of noradrenaline in the central nervous system is responsible for the inhibition of oxotremorine tremor. In this connection it is interesting to note that Corrodi, Fuxe, Hammer, Sjoqvist \& Ungerstedt (1967) found widespread excitation by oxotremorine of central noradrenergic and dopaminergic neurones but not of central 5-HT neurones.

The present results on inhibition of oxotremorine tremor by pretreatment with ( \pm )- $\alpha$-methylmetatyrosine and with diethyldithiocarbamic acid differ from those obtained previously. Agarwal \& Bose (1967) obtained no inhibition of the tremorine tremor in mice after pretreatment with $( \pm)-\alpha$-methylmetatyrosine. However, they gave $100 \mathrm{mg} / \mathrm{kg}$ only of this tyrosine derivative. In the present experiments $400 \mathrm{mg} / \mathrm{kg}$ were given, but even this dose was relatively little effective in inhibiting tremor and would reduce the noradrenaline of the brain in rats by $75 \%$. The difference between the present results and those obtained by Agarwal \& Bose may therefore be due to the fact that the dose of the metatyrosine derivative used by these authors was too small to reveal its tremor-inhibiting property and to reduce significantly the noradrenaline of the brain. Whether the same kind of explanation accounts for the difference between the present results and those obtained by Pfeifer, Galambos \& Gyorgy (1966) with diethyldithiocarbamic acid is not certain. In the present experiments on rats inhibition of oxotremorine tremor was obtained after two injections of $500 \mathrm{mg} / \mathrm{kg}$, whereas Pfeifer et al. detected no inhibition of the tremorine tremor in mice after one injection of $400 \mathrm{mg} / \mathrm{kg}$, although in rats this dose would, according to Carlsson et al. (1966), give a $70 \%$ reduction in brain noradrenaline. It is not known, however, if this compound is as effective in mice as in rats in reducing brain noradrenaline.

It is also not certain whether the inhibition produced by the two peripheral blocking drugs, propranolol, a $\beta$-adrenoceptor and phenoxybenzamine, an $\alpha$-adrenoceptor antagonist, is a peripheral or central effect. The results obtained with propranolol are in agreement with those of previous authors who found propranolol to be an effective antagonist of tremorine (Agarwal \& Bose, 1967 ; Jacobi, 1967). A peripheral action of propranolol is suggested from results obtained by Marsden, Meadows, Lange \& Watson (1967) on man. These authors found that stimulation of peripheral $\beta$-receptors can increase physiological tremor. Hermansen (1968) found propranolol did not affect the oxotremorine induced analgesia and hypothermia in mice. Thus, there is an apparent anomaly between the present findings and those of Hermansen. This could be explained by the hypothesis that oxotremorine tremor is mediated through peripheral propranolol-sensitive receptors, whereas no such receptors are involved in the peripheral mediation of oxotremorineinduced analgesia or hypothermia.

As the inhibition of oxotremorine tremor produced by phenoxybenzamine was associated with abolition of the parasympathetic effects produced by oxotremorine, the phenoxybenzamine may exert its tremor inhibiting effect by an atropine-like action; on the other hand, the inhibition may result from depletion of tissue noradrenaline, an effect which is brought about by phenoxybenzamine (Farrant, Harvey \& Pennefather, 1964). 
It is unlikely that the inhibition of oxotremorine tremor produced by the various drugs is related to their sedative action, because, if reduction of background activity is taken as a measure of sedation, no parallelism was found between reduction in background activity and inhibition of tremor. Reduction in background activity occurred with reserpine and ( \pm )- $\alpha$-methylmetatyrosine but not with diethyldithiocarbamic acid, but all three drugs inhibited the oxotremorine tremors. Nor can increased toxicity to oxotremorine be responsible for the inhibition of tremor, because it occurred after reserpine and phenoxybenzamine and not after diethyldithiocarbamic acid and propranolol, although all four compounds inhibited oxotremorine-induced tremor.

The results obtained on the acetylcholine content of the brain after pretreatment with drugs lend no support to the view that release of acetylcholine in the brain is responsible for the tremorgenic action of oxotremorine, although oxotremorine itself increases the acetylcholine content of the brain. However, after pretreatment with either reserpine or propranolol, which reduced the oxotremorine tremor, the acetylcholine content of the brain was unchanged and oxotremorine still increased the content. Pretreatment with diethyldithiocarbamic acid resulted in a significant increase in the acetylcholine content of the brain, but this drug caused inhibition of oxotremorine tremor, not potentiation.

Oxotremorine was obtained as a gift from two sources; Dr. A. K. Cho, Department of Pharmacology, U.C.L.A., Los Angeles, California, U.S.A., and Dr. R. W. Brimblecombe, Ministry of Defence, Chemical Defence Establishment, Porton Down, Wilts.

\section{REFERENCES}

Agarwal, S. L. \& Bose, D. (1967). A study of the role of brain catecholamines in drug induced tremor. Br. J. Pharmac. Chemother., 30, 349-353.

Carlsson, A. (1965). Drugs which block the storage of 5-hydroxytryptamine and related amines. In Handbook of Experimental Pharmacology (New Series), vol. XIX, 5-hydroxytryptamine and related indolealkylamines, ed. Eichler, O. \& Farah, A., pp. 529-592. Berlin: Springer-Verlag.

Carlsson, A., Lindevist, M., FuXe, K. \& Hokfelt, T. (1966). Histochemical and biochemical effect of diethyldithiocarbamate on tissue catecholamines. J. Pharm. Pharmac., 18, 60-62.

Corrodi, H., Fuxe, K., Hammer, W., SJoqvist, F. \& Ungerstedt, U. (1967). Oxotremorine and central monoamine neurons. Life Sci., Oxford, 6, 2557-2566.

Cox, B. \& PotKonjaK, D. (1967). The effect of ambient temperature on the actions of tremorine on body temperature and on the concentration of noradrenaline, dopamine, 5-hydroxytryptamine and acetylcholine in rat brain. Br. J. Pharmac. Chemother., 31, 356-366.

Cox, B. \& Potkonjak, D. (1969a). The effects of atropine and dyflos on the tremor and increase in whole brain acetylcholine produced by injection of oxotremorine in the rat. Br. J. Pharmac., 35, 521-529.

Cox, B. \& Potkonjak, D. (1969b). The relationship between tremor and change in brain acetylcholine concentration produced by injection of tremorine or oxotremorine in the rat. $B r . J$. Pharmac., 35, 295-303.

EVERETT, G. M. (1967). Effects of oxotremorine on the biogenic and cholinergic systems in rat and mouse CNS. Fedn Proc., 26, 764.

Farrant, J., Harvey, J. A. \& Pennefather, J. N. (1964). The influence of phenoxybenzamine on the storage of noradrenaline in rat and cat tissues. Br. J. Pharmac. Chemother., 22, $104-112$.

Friedman, A. H. \& Everett, G. M. (1964). Pharmacological aspects of parkinsonism. Adv. Pharmac., 3, 83-127.

HAMMER, W. \& SJOQVist, F. (1967). Inhibition of the metabolism of tremorine and oxotremorine in rats by antidepressants of the imipramine type. In International Symposium on Antidepressant Drugs, Milan, ed. Garattini, S. \& Dukes, M. N. G., pp. 279-289. Amsterdam: Excerpta Medica Foundation.

HeRmansen, K., (1968). Some pharmacological properties of a new $\beta$-adrenergic blocking agent, 1, (isopropylamino-3-(O-phenoxyphenoxy)-2-propranol, HCL (PhQA 33). Acta pharmac. tox., 26, 343-362.

Hess, S. M., Connamacher, R. H., Ozaki, M. \& Udenfriend, S. (1961). The effects of $a$-methyldopa and $a$-methylmetatyrosine on the metabolism of norepinephrine and serotonin in vivo. $J$. Pharmac. exp. Ther., 134, 129-138. 
JACOBI, H. (1967). Hemmung des tremors durch $\beta$-adrenolytisch wirksame substanzen. Naturwissenschaften, 54, 94.

Koe, K. B. \& Weissman, A. (1966). p-Chlorophenylalanine: A specific depletor of brain serotonin. J. Pharmac. exp. Ther., 154, 499-516.

Marsden, C. D., Meadows, J. C., LANGe, G. W. \& Watson, R. S. (1967). Effect of deafferentation on human physiological tremor. Lancet, 2, 700-702.

MORPUGO, C. (1967). Interaction of imipramine and desmethylimipramine with tremorine and oxotremorine in mice. Life Sci., Oxford, 6, 721-731.

Patten, B. M., Sakamoto, A., Van Woert, M. H., Papayasiliou, P. S. \& Cotzias, G. C. (1964). Tremorine-induced tremor versus extrapyramidal disease. Nature, Lond., 201, 929-930.

Pfeifer, A. K., Galambos, E. \& Gyorgy, L. (1966). Some central nervous properties of diethyldithiocarbamate. J. Pharm. Pharmac., 18, 254.

Sieger, S. (1956). Nonparametric Statistics for the Behavioural Sciences. London: McGraw-Hill.

SJoqvist, F. \& Gillette, J. (1965). Prolongation and potentiation of oxotremorine effects by desmethylimipramine, an antitremorine drug. Life Sci., Oxford, 4, 1031-1036.

SPENCER, P. S. J. (1966). The antagonism of oxotremorine effects in the mouse by thymoleptics. Life Sci., Oxford, 5, 1015-1023.

(Received June 27, 1969) 